\title{
Effectiveness of a Health Educational Program Based on Self-Efficacy and Social Support for Preventing Liver Fluke Infection in Rural People of Surin Province, Thailand
}

\author{
Soraya J Kaewpitoon ${ }^{2,3,4 *}$, Sirisuda Thanapatto ${ }^{1}$, Wimonya Nuathong ${ }^{6}$, Ratana \\ Rujirakul $^{1}$, Parichart Wakkuwattapong ${ }^{1}$, Jun Norkaew ${ }^{6}$, Jirawoot Kujapun ${ }^{6}$, \\ Natnapa Padchasuwan ${ }^{7}$, Natthawut Kaewpitoon ${ }^{2,3,6}$
}

\begin{abstract}
Opisthorchiasis is a major problem in Thailand particularly in northeast region which also has a high incidence of cholangiocarcinomas. Since health modification is needed, this quasi-experimental study aimed to assess the effectiveness of a health education program based on self-efficacy and social support in Tha Tum district, Surin province, Thailand. A total of $\mathbf{7 0}$ participants were purposive selected with a history of opisthorchiasis. Participants were divided into experimental and control groups, each with 35 subjects. The experimental group received a health education program composed of: (1) knowledge improvement, lectured with multimedia, demonstration, brochure, and handbook; (2) group discussion about their health beliefs, sharing their ideas and experience; and (3) social support from village health volunteers (VHV), heads of villages (HV), friends, and members of families, and public health officer (PHO). Follow-up was by $\mathrm{PHO} / \mathrm{VHV} / \mathrm{HV}$, with provision of certificates and flasg for household that did not eat raw fish. Data were collected by predesigned questionnaires after implementation of the program for 3 months. Comparative data was analyzed by paired simple $t$-test and independent t-test. The results revealed that the experimental group had mean score of knowledge higher more than before the experiment (mean difference $=3.1, t=3.915,95 \% \mathrm{CI}-3.3,-1.8 \mathrm{p}$-value $=0.001$ ), and the control group (mean difference $=2.5, \mathrm{t}=4.196,95 \% \mathrm{CI}=1.4,3.6$, $\mathrm{p}$-value $=0.001$ ) with statistical significance. The mean scores of practice were higher than before the experiment (mean difference $=4.6, t=4.331,95 \% \mathrm{CI}-5.3,-3.1, \mathrm{p}$-value $=0.001$ ), and control group (mean difference $=4.4, t=6.142,95 \% \mathrm{CI}=4.2,7.9, \mathrm{p}$-value $=0.001$ ) . The mean scores of perceived susceptibility and perceived severity of opisthorchiasis, al well as perceived benefits and perceived barriers to prevention of opisthorchiasis, were also higher than before the experiment and in the control group (p-value $<0.001)$. In conclusion, this was a successful health education program for liver fluke avoidance. Therefore, it may useful for further behavior modification in the other epidemic areas.
\end{abstract}

Keywords: Educational program - self-efficacy theory - social support model - liver fluke - Thailand

Asian Pac J Cancer Prev, 17 (3), 1111-1114

\section{Introduction}

Liver fluke infection caused by O. viverrini remains a major public health problem in many parts of Southeast Asia including Thailand, Lao PDR, Vietnam and Cambodia (IARC, 1994; Kaewpitoon et al., 2008b; Sripa et al., 2010; Sitthithaworn et al., 2012; Kaewpitoon et al., 2015a). Infection is acquired by ingestion of undercooked cyprinoid's fish harboring infective metacercariae (Kaewkes 2003). Liver fluke is endemic among human populations in northeast and north Thailand, where the most common raw fish "Koi pla" is frequently consumed
(Sadun 1955; Harinasuta and Vajrasthira 1960; Wykoff et al., 1965; Preuksaraj et al., 1982). A nationwide survey in Thailand found that the prevalent was $5.1 \%$. The highest of prevalent was found in the northeast $(9.2 \%)$ and followed by the north region (5.2\%). Top five of prevalent with opisthorchiasis were reported in Nakhon Panom (23.2\%), Buriram (17.6\%), Roi Et (15.5\%), Srisaket (14.3\%), and Surin province $(14.3 \%)$, respectively (Wongsaroj et al., 2014). The provincial wide survey in Surin province, Thailand was reported that Tha Tum (16.7\%) and Sang Kha district (16.7\%) of were the highest of infection (Kaewpitoon et al., 2015b).

${ }^{1}$ Parasitic Disease Research Unit, ${ }^{2}$ School of Family Medicine and Community Medicine, ${ }^{3}$ Suranaree University of Technology Hospital, Suranaree University of Technology, ${ }^{4}$ Faculty of Public Health, ${ }^{5}$ Mathematics and Applied Statistic Program, Faculty of Science and Technology, Nakhon Ratchasima Rajabhat University, ${ }^{6}$ Faculty of Public Health, Vongchavalitkul University, Nakhon Ratchasima, ${ }^{7}$ Faculty of Public Health, Khon Kaen University, Khon Kaen, Thailand *For correspondence: soraya.k@sut.ac.th 
Behavior on prevention and control of liver fluke infection are essential for decreasing the disease. Previously studied indicated that knowledge, attitude, and practice related to liver fluke infection in rural communities (Kaewpitoon et al., 2007). Therefore, health modification is need required in this areas particularly improvement of corrected knowledge, and practice in the risk group or people who had a history with opisthorchiasis. Improvement of high knowledge, perception, and practice regarding diseases, depend on varieties of health education. Boom (1971), Becker and Maiman (1975), and Janz and Becker (1984) indicated that the success behavior modification should be used many methods and continuous intervention. In addition, self-efficacy and social support influencing behavior modification, common used in the health education program (House and Kahn 1985).

According a serious data on liver fluke in the epidemic areas, therefore, this study aimed to study the effectiveness of health education program based on self-efficacy and social support model on liver fluke in Tha Tum district, Surin province, Thailand. The health education program may useful and effective toward liver fluke prevention and control in the epidemic communities.

\section{Materials and Methods}

A quasi-Experimental study was approved by the human research ethics committees of Suranaree University of Technology, 2013. The study was performed during October 2014 to July 2015 in Tha Tum district, Surin province, northeastern Thailand where reported the epidemic areas. Of 70 participants was assigned to 2 groups; 35 participants were experimental group and received health education programs, meanwhile 35 participants were a control group that without the same health education program. Health education program was applied based on self-efficacy and social support theory for health behavioral modification regarding liver fluke. Health education program included Week 1; knowledge improvement which composed of lectured with multimedia, demonstration regarding general knowledge on the epidemiology, morphology, life cycle, transmission, sign and symptoms, pathogenesis, related diseases, diagnosis, treatment, prevention and control of liver fluke, Week 2; lectured with poster, brochure, and handbook regarding general knowledge toward liver fluke similar to week 1 , Week 3; lectured toward susceptibility and severity of opisthorchiasis, benefits and perceived barriers to prevention of opisthorchiasis, Week 4; group discussion with their health belief, sharing their ideas and experience toward liver fluke prevention and control, and Week 5-10; social support from village health volunteers (VHV), head village (HV), friends, their member of family, and public health officer (PHO). The followed-up by $\mathrm{PHO} / \mathrm{VHV} / \mathrm{HV}$, and giving certificates and flag for household that did not eat raw fish. The study was implemented for 10 weeks. Pre-and-post-test was measured with questionnaires.

A predesigned questionnaire containing 4 parts included (1) demographic characteristics; gender, age, marital status, education, occupation, and income,
(2) knowledge, (3) perceive; susceptibility, severity, benefit and barrier, and (4) practice regarding liver fluke prevention and control. Each questionnaire was analyzed and interpreted for their parts. Evaluation of knowledge was calculated and analyzed according to Bloom (1971). Knowledge with 15 questions, answer correct $=1$, incorrect $=0$, and interpreted to high level; $\geq 80 \%$ points, moderate level; $60 \%-79.5 \%$ points, $0-59.5 \%$ points; low level. Perceive and practice level were calculated and analyzed according to Best (1977). Perceive with 9 questions; 3 choice (agree, not sure, disagree): positive question $=3,2,1$, negative question $=1,2,3$, and interpreted to high level; 21.6-27 points, moderate level; 16.2-21.5 points, and low level; 0-16.1 points. Evaluation of practical level with 9 question; 3 choice (frequently, sometimes, never): positive question=3,2,1, negative question=1,2,3, and interpreted to high level; 21.6-27 points, moderate level; $16.2-21.5$ points, and low level; 0-16.1 points. The questionnaires were completed a content validity by 3 experts on liver fluke knowledge, and then tryout in closely neighbor communities for reliability test. The questionnaires has reliability value according to knowledge part with Kuder-Richardson-20: KR-20 $=0.78$, perceive and practice with Cronbach's Alpha Coefficient $=0.75,0.73,0.73$, and 0.76. Descriptive and analytical statistical data were analyzed with SPSS software. Percentage, mean, standard deviation, Paired $\mathrm{t}$ - test, Independent $\mathrm{t}$ - test, the statistical significance level of .05 were employed for data analyzes.

Table 1. Demographical Characteristics of Experimental and Control Groups

\begin{tabular}{|c|c|c|c|c|}
\hline \multirow{2}{*}{$\begin{array}{l}\text { Demographical } \\
\text { characteristic }\end{array}$} & \multicolumn{2}{|c|}{ Experiment $(n=35)$} & \multicolumn{2}{|c|}{ Control $(n=35)$} \\
\hline & No & $\%$ & No & $\%$ \\
\hline \multicolumn{5}{|l|}{ Gender } \\
\hline Male & 7 & 20 & 10 & 28.6 \\
\hline Female & 28 & 80 & 25 & 71.4 \\
\hline \multicolumn{5}{|l|}{ Age (year old) } \\
\hline $15-30$ & 1 & 2.9 & 12 & 34.3 \\
\hline $31-50$ & 17 & 48.6 & 12 & 34.3 \\
\hline $51-70$ & 17 & 48.6 & 4 & 11.4 \\
\hline \multicolumn{5}{|l|}{ Marital status } \\
\hline Single & 1 & 2.9 & 5 & 14.3 \\
\hline Married & 28 & 80 & 25 & 71.4 \\
\hline Widowed & 5 & 14.3 & 4 & 11.4 \\
\hline Separated & 1 & 2.9 & 1 & 2.9 \\
\hline \multicolumn{5}{|l|}{ Education } \\
\hline Uneducated & 0 & 0 & 2 & 5.7 \\
\hline Primary School & 30 & 85.7 & 26 & 74.3 \\
\hline Junior Secondary School & 2 & 5.7 & 4 & 11.4 \\
\hline High School & 2 & 5.7 & 1 & 2.9 \\
\hline Diploma & 1 & 2.9 & 1 & 2.9 \\
\hline Undergraduate & 0 & 0 & 1 & 2.9 \\
\hline \multicolumn{5}{|l|}{ Occupation } \\
\hline Agriculture & 31 & 88.6 & 25 & 71.4 \\
\hline Business & 2 & 5.7 & 3 & 8.6 \\
\hline Employee & 2 & 5.7 & 7 & 20 \\
\hline \multicolumn{5}{|l|}{ Income (Thai Baht) } \\
\hline$>4,000 \mathrm{Baht}$ & 22 & 62.9 & 34 & 97.1 \\
\hline $4,000-8,000$ Baht & 7 & 20 & 1 & 2.9 \\
\hline$>8,000$ Bath & 6 & 17.1 & 0 & 0 \\
\hline
\end{tabular}


Table 2. Compared Mean Scores for Knowledge, Perceive, and Practice Regarding Liver Flukes, within group of the experimental and control groups

\begin{tabular}{|c|c|c|c|c|c|c|}
\hline Knowledge, Perceive, Practice & $\begin{array}{c}\text { Before } \\
\text { Mean } \pm \text { SD }\end{array}$ & $\begin{array}{c}\text { After } \\
\text { Mean } \pm S D\end{array}$ & Meandifference & $\mathrm{t}$ & $95 \% \mathrm{CI}$ & $\mathrm{p}$-value \\
\hline \multicolumn{7}{|l|}{ Experimental group (35) } \\
\hline Knowledge & $10.0 \pm 1.7$ & $13.1 \pm 1.8$ & 3.1 & 3.915 & $-3.3,-1.8$ & 0.001 \\
\hline Perceive susceptibility & $18.4 \pm 2.1$ & $23.6 \pm 1.1$ & 5.2 & 4.924 & $-4.3,-1.9$ & 0.001 \\
\hline Perceive severity & $19.1 \pm 1.9$ & $23.2 \pm 0.9$ & 4.1 & 4.251 & $-6.8,-3.7$ & 0.001 \\
\hline Perceive benefit and barrier & $18.1 \pm 2.0$ & $24.4 \pm 2.0$ & 6.3 & 5.318 & $-3.8,-1.2$ & 0.001 \\
\hline Practice & $18.5 \pm 1.7$ & $23.1 \pm 1.4$ & 4.6 & 4.331 & $-5.3,-3.1$ & 0.001 \\
\hline \multicolumn{7}{|l|}{ Control group (35) } \\
\hline Knowledge & $10.3 \pm 1.8$ & $10.9 \pm 1.6$ & 0.6 & 0.214 & $-0.1,2.2$ & 0.092 \\
\hline Perceive susceptibility & $18.3 \pm 1.1$ & $18.9 \pm 1.2$ & 0.6 & 0.221 & $-0.8,0.6$ & 0.441 \\
\hline Perceive severity & $18.7 \pm 1.0$ & $18.9 \pm 1.3$ & 0.2 & 0.526 & $-1.4,0.6$ & 0.079 \\
\hline Perceive benefit and barrier & $18.2 \pm 1.8$ & $18.7 \pm 1.1$ & 0.5 & 0.371 & $-2.1,0.1$ & 0.314 \\
\hline Practice & $18.9 \pm 1.8$ & $19.1 \pm 1.7$ & 0.2 & 0.552 & $-1.5,0.5$ & 0.095 \\
\hline
\end{tabular}

Table 3. Compared Mean Scores for Knowledge, Perceive, and Practice Regarding Liver Flukes, Between Groups of the Experimental and Control Groups

\begin{tabular}{|c|c|c|c|c|c|c|c|}
\hline Knowledge, Perceive, Practice & $\mathrm{n}$ & d & $\mathrm{SD}$ & Mean difference & $\mathrm{t}$ & $95 \% \mathrm{CI}$ & p-value \\
\hline \multicolumn{8}{|l|}{ Knowledge } \\
\hline Experimental group & 35 & 3.1 & 2.5 & 2.5 & 4.196 & $1.4,3.6$ & 0.001 \\
\hline Control group & 35 & 0.6 & 2.6 & & & & \\
\hline \multicolumn{8}{|l|}{ Perceive susceptibility } \\
\hline Experimental group & 35 & 5.2 & 5.3 & 4.6 & 6.418 & $4.4,8.3$ & 0.001 \\
\hline Control group & 35 & 0.6 & 4.1 & & & & \\
\hline \multicolumn{8}{|l|}{ Perceive severity } \\
\hline Experimental group & 35 & 4.1 & 4.1 & 3.9 & 5.241 & $2.2,5.3$ & 0.001 \\
\hline Control group & 35 & 0.2 & 3.7 & & & & \\
\hline \multicolumn{8}{|l|}{ Perceive benefit and barrier } \\
\hline Experimental group & 35 & 6.3 & 5.1 & 5.8 & 6.829 & $4.5,8.1$ & 0.001 \\
\hline Control group & 35 & 0.5 & 4.0 & & & & \\
\hline \multicolumn{8}{|l|}{ Practice } \\
\hline Experimental group & 35 & 4.6 & 5.2 & 4.4 & 6.142 & $4.2,7.9$ & 0.001 \\
\hline Control group & 35 & 0.2 & 3.6 & & & & \\
\hline
\end{tabular}

\section{Results}

The majorities of participants were female $(80.0 \%)$, age between $31-70$ years old $(48.6 \%)$, married $(80.0 \%)$, primary school $(85.7 \%)$, agriculture $(88.6 \%)$, and income $<4,000$ Baht (Table 1). The results reveal that after the experiment, experimental group had mean score of knowledge higher more than before the experiment (mean difference $=3.1, \mathrm{t}=3.915$, 95\%CI$3.3,-1.8 \mathrm{p}$-value $=0.001)$, and control group (mean difference $=2.5, \mathrm{t}=4.196,95 \% \mathrm{CI}=1.4,3.6$, $\mathrm{p}$-value $=0.001$ ) with a statistical significantly. The results also found that after the experiment, experimental group had mean score of practice higher more than before the experiment (mean difference $=4.6, \mathrm{t}=4.331,95 \% \mathrm{CI}-5.3,-3.1$, $\mathrm{p}$-value $=0.001)$, and control group $($ mean difference $=4.4$, $\mathrm{t}=6.142,95 \% \mathrm{CI}=4.2,7.9, \mathrm{p}$-value $=0.001)$ with statistical significantly. The perceived susceptibility and perceived severity of opisthorchiasis, perceived benefits and perceived barriers to prevention of opisthorchiasis, more than before the experiment and control group was significantly (p-value $<0.001)$. All data was shown in Table 2 and 3.

\section{Discussion}

Development of a community-based approach to opisthorchiasis control has been recommended (Duangsong et al., 2013). Toward integrated opisthorchiasis control in northeast Thailand: the Lawa project was showed to be the best model (Sripa et al., 2015). Community-based health education and communication model development for opisthorchiasis prevention has been also implemented in a high-risk area, Khon Kaen Province, Thailand (Promthet et al., 2015). This quasi-experimental study was conducted in the epidemic areas where is the top ten of high prevalence of liver fluke infection in Thailand (Wongsaroj et al., 2014). All participants was purposive selected from who had a history with opisthorchiasis. The majorities of participants were female $(80.0 \%)$, age between 31 70 years old $(48.6 \%)$, married $(80.0 \%)$, primary school $(85.7 \%)$, agriculture $(88.6 \%)$, and income $<4,000$ Baht. This recent results is similar to that several approaches for reducing opisthorchiasis-linked CCA. All participants were 30-69 years of age. Of all the participants, more than $60 \%$ had regularly participated in activities to prevent CCA following health official advice. Age and health behavior to prevent CCA were factors associated with community participation for CCA $(\mathrm{p}<0.001)$ (Songserm 
et al., 2015).

Recently, the results reveal that after the experiment, experimental group had mean score of knowledge more than before the experiment and control group. This result is similar to that Boom (1971) suggested the success of behavioral modification should be composed varieties activities. Here, we have lectured, demonstrated, and trained. Therefore, experimental group had a high score of knowledge. Furthermore, after experiment, the experimental group had a high mean score of perception more than before and control group, this similarly to Becker and Maiman (1975), and Janz and Becker (1984). Discussion and sharing of the perceived susceptibility and perceived severity of opisthorchiasis, perceived benefits and perceived barriers to prevention of opisthorchiasis, effecting their improve perception. In addition, the results indicate that the experimental group had mean score of practice more than before the experiment and control group. This continuous good practice is dependent on social support that influencing behavior modification, this is similarly to House and Kahn (1985).

This health education program is success to health behavior modification in the rural communities therefore it may useful for further work behavior modification in the other epidemic areas.

\section{Acknowledgements}

This work was supported by Suranaree University of Technology (SUT) and by Office of the Higher Education Commission under NRU Project of Thailand.

\section{References}

Becker MH, Maiman LA (1975). A new approach to explaining sick role behavior in low income population American of Public Health. Southeast Asian J Trop Med Public Health, 3, 330-6.

Best JW (1977). Research in education (3rd ed). Englewood Cliffs, NJ: Prentice-Hall.

Bloom BS. (1971). Handbook on formative and summative of student learning. New York: Mc Graw-Hill Book Company.

Harinasuta C, Vajrasthira S (1960). Opisthorchiasis in Thailand. Ann Trop Med Parasitol, 54, 100-05.

House JS, Kahn RL (1985). Measures and concepts of social support. In S. Cohen \& S. L. Syme (Eds.), Social support and health. New York, NY: Academic Press, 83-108

IARC. (1994). Infection with liver flukes (Opisthorchis viverrini, Opisthorchis felineus and Clonrochis sinensis). IARC Monogr Eval Carcinog Risks of Hum, 61, 121-75.

Janz NK, Becker MH (1984). The health belief model: A decade later. Health education Quarterly, 11, 1-47.

Kaewkes S (2003). Taxonomy and biology of liver flukes. Acta Trop, 88, 177-86.

Kaewpitoon N, Kaewpitoon SJ., Pengsaa P., et al (2007). Knowledge, attitude and practice related to liver fluke infection in northeast Thailand. World J Gastroenterol, 13, 1837-40.

Kaewpitoon N, Kaewpitoon SJ, Pengsaa P(2008). Opisthorchiasis in Thailand: review and current status. World J Gastroenterol, 14, 2297-302.

Kaewpitoon N, Kaewpitoon SJ, Pengsaa P, et al (2008). Opisthorchis viverrini: the carcinogenic human liver fluke. World J Gastroenterol, 14, 666-74.
Kaewpitoon SJ, Kaewpitoon N, Rujirakul et al (2015). The Carcinogenic Liver Fluke Opisthorchis viverrini among Rural Community People in Northeast Thailand: a CrossSectional Descriptive Study using Multistage Sampling Technique. Asian Pac J Cancer Prev, 16, 7803-7.

Kaewpitoon N, Kootanavanichpong N, Kompor P, et al (2015). Review and Current Status of Opisthorchis viverrini Infection at the Community Level in Thailand. Asian Pac J Cancer Prev, 16, 6825-30

Preuksaraj S, Jeeradit C, Satilthai A, et al (1982). Prevalence and intensity of intestinal helminthiasis in rural Thailand. Con Dis J, 8, 221-69.

Sadun EH (1955). Studies on Opisthorchis viverrini in Thailand. Am J Hyg, 62, 81-115.

Sithithaworn P, Andrews RH, Nguyen VD, et al (2012). The current status of opisthorchiasis and clonorchiasis in the Mekong Basin. Parasitol Int, 61, 10-6.

Songserm N, Bureelerd O, Thongprung S, et al (2015). Community participation in cholangiocarcinoma prevention in ubon ratchathani, Thailand: Relations with Age and Health Behavior. Asian Pac J Cancer Prev, 16, 7375-9.

Sripa B, Kaewkes S, Intapan PM, et al (2010). Food-borne trematodiases in Southeast Asia: epidemiology, pathology, clinical manifestation and control. Adv Parasitol, 72, 305-50.

Sripa B, Tangkawattana S, Laha T, et al (2015). Toward integrated opisthorchiasis control in northeast Thailand: the Lawa project. Acta Trop, 141, 361-7.

Thamavit W, Bhamarapravati N, Sahaphong S, et al. (1978). Effects of dimethylnitrosamine on induction of cholangiocarcinoma in Opisthorchis viverrini-infected Syrian golden hamsters. Cancer Res, 38, 4634-9.

Wongsaroj T, Nithikathkul C, Rojkitikul Wet al (2014). National survey of helminthiasis in Thailand. Asian Biomedicine, $\mathbf{8}$, 779-83

Wykoff DE, Harinasuta C, Juttijutada P, Winn MM (1965). Opisthorchis viverrini in Thailand-the life cycle and comparison with O. felineus. J Parasitol, 51, 207-14. 